\title{
PULSUS RESPIROLOGY NEWS
}

\section{Norman L Jones Award}

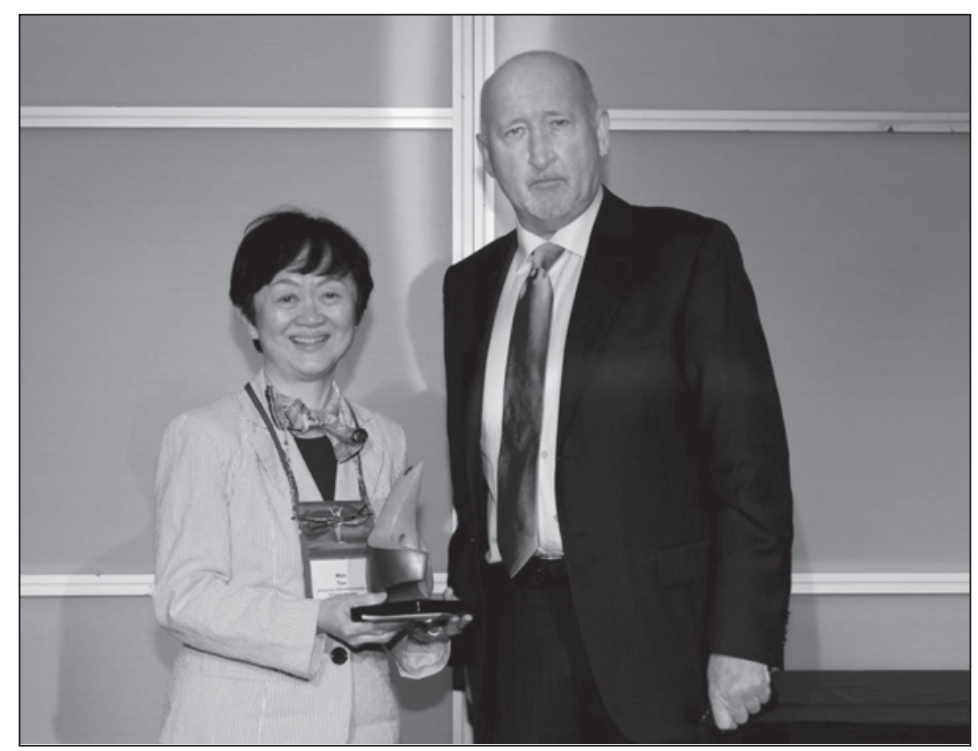

Robert Kalina (right), Publisher of the Canadian Respiratory Journal, with the 2012 winner of the Dr Norman L Jones Award Dr Wan Tan (Vancouver, British Columbia) who, with the COLD Study investigators (J Bourbeau, P Hernandez, K Chapman, R Cowie, MJ FitzGerald, S Aaron, DD Marciniuk, F Maltais, DE O'Donnell, R Goldstein and D Sin) and the LHCE study investigators (M Chan-Yeung, J Manfreda, NR Anthonisen, RB Tate, MR Sears, HC Siersted, MR Becklake, P Ernst, DM Bowie, L Sweet and L Van Til) authored 'Canadian prediction equations of spirometric lung function for Caucasian adults 20 to 90 years of age: Results from the Canadian Obstructive Lung Disease (COLD) study and the Lung Health Canadian Environment (LHCE) study' (Can Respir J Vol 18 No 6 Nov/Dec 2011). This award, sponsored by Pulsus Group Inc, was presented at the recent Canadian Respiratory Conference held in Vancouver, and carries with it a cheque in the amount of $\$ 1,000$ and a piece of Canadian art. 


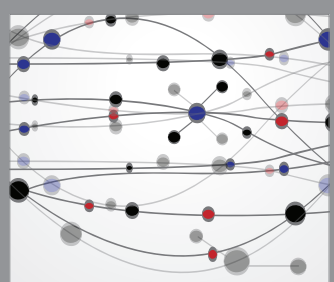

The Scientific World Journal
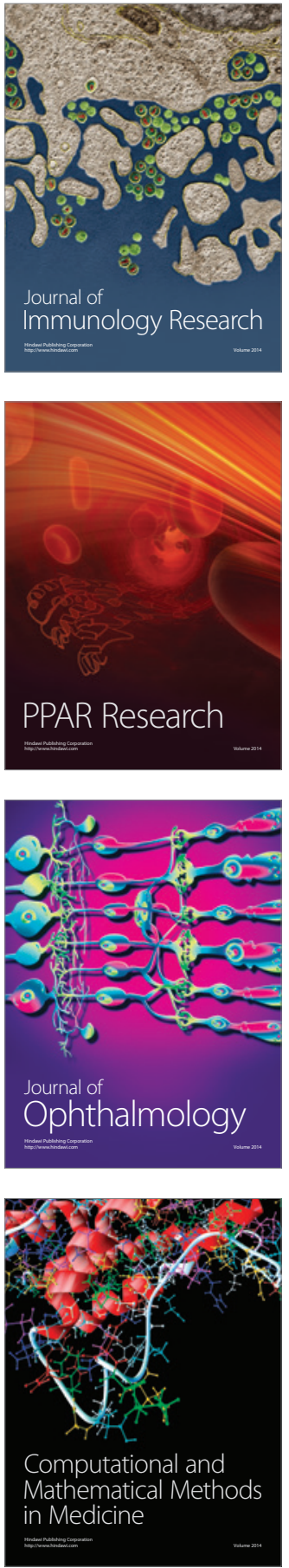

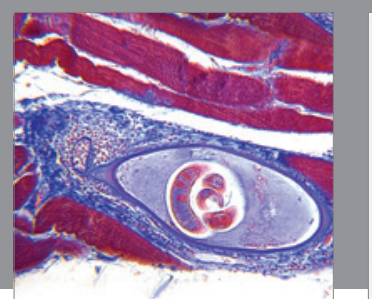

Gastroenterology Research and Practice

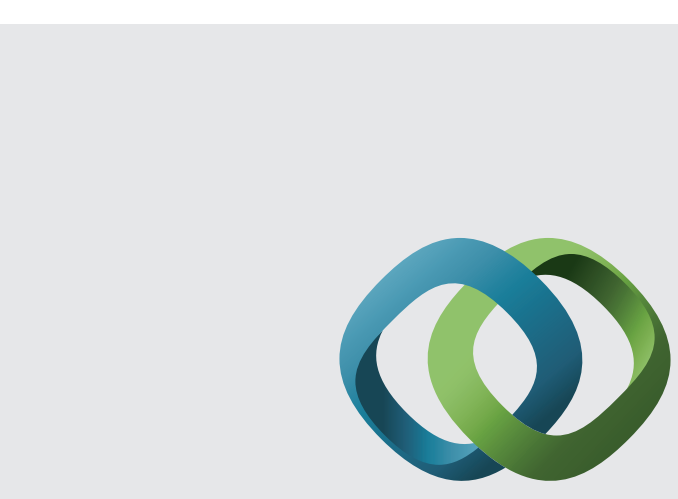

\section{Hindawi}

Submit your manuscripts at

http://www.hindawi.com
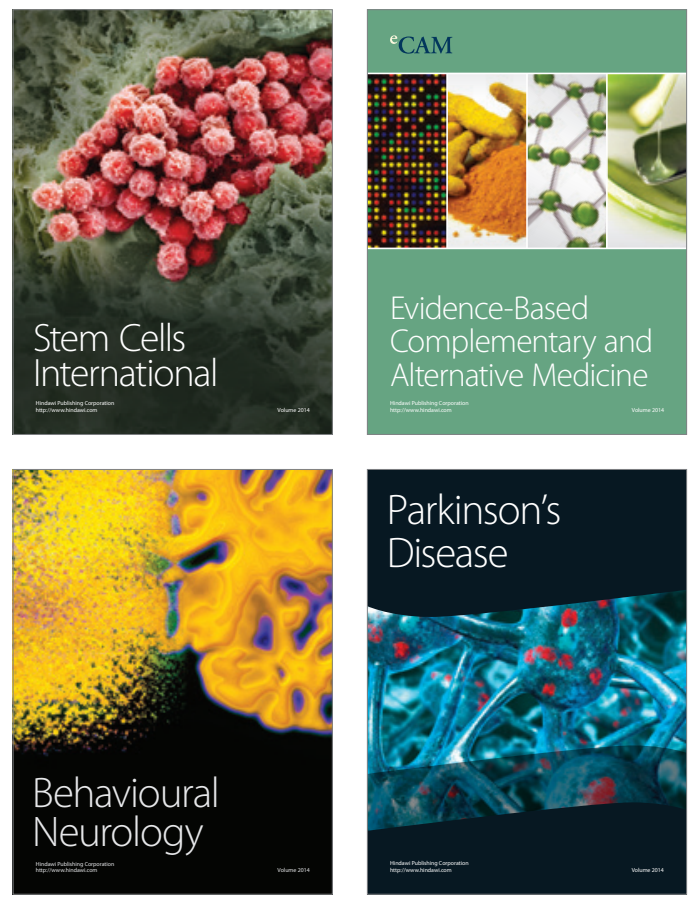
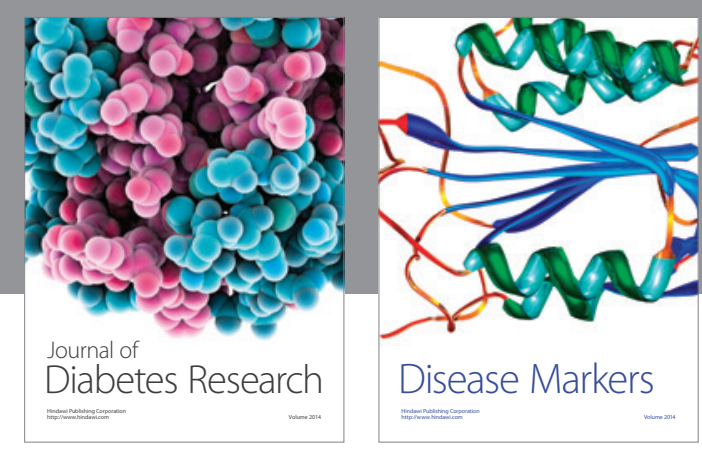

Disease Markers
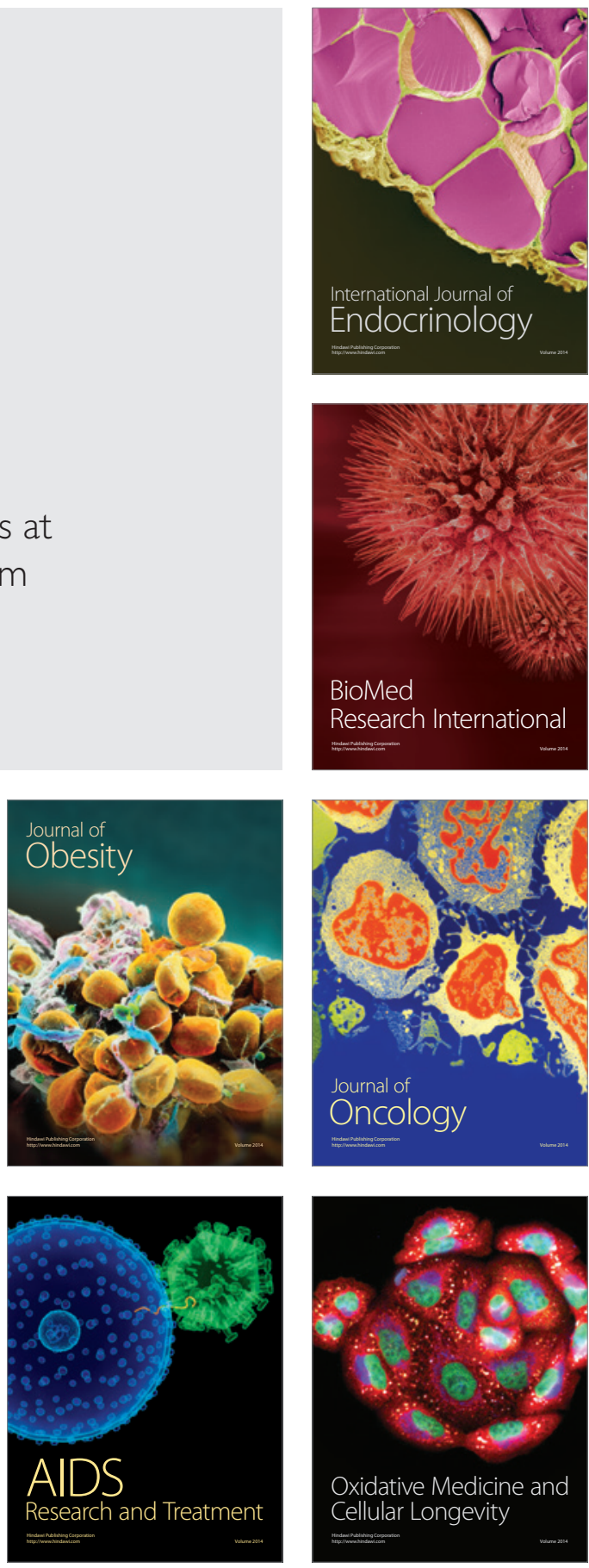